\title{
RELAÇÕES HÍDRICAS EM POVOAMENTO DE EUCALIPTO COM DIFERENTES DENSIDADES POPULACIONAIS ${ }^{(1)}$
}

\author{
F. P. LEITE (2), N. F. BARROS(3), R. F. NOVAIS(3), \\ L. M. A. SANS ${ }^{(4)} \&$ A. S. FABRES ${ }^{(5)}$
}

\begin{abstract}
RESUMO
E m experimento realizado na região de Santa Bárbara (MG), no período de agosto de 1994 a fevereiro de 1995, avaliaram-se a precipitação pluviométrica interna, a evapotranspiração da cultura (ETC) e o regime hídrico do solo sob povoamento de E ucalyptus grandis (dos 32 aos 38 meses de idade) com densidades populacionais variando de 500 a 5.000 plantas ha $^{-1}$. A umidade volumétrica do solo, em uma seção de controle de 0 a $285 \mathrm{~cm}$ de profundidade, foi determinada quinzenalmente, por meio de moderação de nêutrons. A interceptação de água pelas copas aumentou linearmente com o aumento da população de plantas, enquanto a ETc não foi significativamente influenciada. A umidade do solo tendeu a aumentar com a redução da população de plantas. A umidade do solo em todas as épocas monitoradas nunca apresentou valores inferiores àquele correspondente à água retida à tensão de 1,5 $\mathrm{MPa}$.
\end{abstract}

Termos de indexação: Eucalyptus grandis, regime hídrico, evapotranspi ração.

\section{SUMMARY: WATER RELATION IN EUCALYPT STANDS AS AFFECTED BY PLANT POPULATION}

In a trial carried out at Santa Barbara, MG, Brazil, the influence of plant population on throughfall, crop evapotranspiration (ETC) and soil moistureregimeof Eucalyptus grandis stands was evaluated. Plant population varied from 500 to 5000 trees ha-1. Soil moisture

(1) Parte da Tese de Mestrado apresentada pelo primeiro autor ao Curso de Pós-graduação em Solos e Nutrição de Plantas da Universidade Federal de Viçosa - UFV. Recebido para publicação em junho de 1996 e aprovado em setembro de 1998.

(2) Rua Ouro, 35, I guaçu, CEP 35162-103 I patinga (MG).

(3) Professor Titular do Departamento de Solos da UFV. CEP 36571-000 Viçosa (MG). Bolsista do CNPq.

(4) Pesquisador da EMBRAPA - Centro Nacional de Pesquisa de Milho e Sorgo. CEP 35701-970 Sete Lagoas (MG).

(5) Pesquisador da Celulose Nipo-Brasileira. CEP 35101-970 I patinga (MG). 
was measured down to a depth of $285 \mathrm{~cm}$ by a neutron probe, every 15 days. Rain water interception increased linearly with increasing plant population, whereas ETc was not significantly influenced. Soil moisturelevel tended to increaseas plant populati on decreased. During the experimental period, soil moisturelevel was never bel ow that corresponding to retained water at $1.5 \mathrm{MPa}$.

Index terms: Eucalyptus grandis, soil moisture, evapotranspiration.

\section{INTRODUÇÃO}

Conhecendo as variações de umidade no solo, é possível avaliar a influência das plantas sobre a disponibilidade de água, fazer inferências a respeito da transpiração das plantas, determinar as regiões onde o sistema radicular atua de modo mais efetivo e outros efeitos da vegetação sobre a água do solo.

Pode-seatribuir o efeito da densidade populacional de plantas sobre o regime hídrico do solo, princi palmente, às diferenças na quantidade deágua transpirada e na interceptação de chuva pela copa. Outros fatores que também devem interferir e podem estar relacionados com a densidade populacional são a interceptação de água pela manta orgânica depositada na superfície do solo, a taxa de infiltração de água no sol o, o escoamento superficial e o microclima dentro de cada povoamento.

Uma das maneiras utilizadas para aumentar o deflúvio é a redução da densidade populacional de árvores na área de captação. Com o desbaste, ocorre redução tanto na transpiração como na interceptação (Stoneman \& Schofield, 1989). McN oughtan \& J arvis (1983), citados por Stoneman \& Schofield (1989), relataram que a redução na transpiração deve ocorrer na mesma proporção da redução da área foliar. Para Kramer (1983), essa proporcionalidade necessariamente não é observada e pode não levar à redução das taxas de transpiração, pois pode haver aumento da taxa de perda de água por unidade de superfície das fol has que permanecerem.

Gomes (1994), avaliando o efeito do espaçamento no cresci mento eas relações hídricas detrês espécies de eucalipto, entre 14 e 26 meses de idade, não detectou influência significativa do espaçamento na condutância estomática (gs). Entretanto, houve tendência de ocorrer maior gs e maior taxa de transpiração nas plantas sob espaçamentos mais amplos.

Este trabalho teve a finalidade de avaliar as variações temporais de água no solo, a relação da umi dade do sol o com o crescimento do eucal ipto, bem como estimar a evapotranspiração ocorrida em parcelas de eucalipto sob diferentes densidades populacionais.

\section{MATERIAL E MÉTODOS}

Este estudo foi realizado em área experimental da CENIBRA Florestal, no município de Santa Bárbara (MG) (1957' de latitude sul, 4324' de longitude oeste e altitude de $740 \mathrm{~m}$ ). Pela classificação de Köppen, a região tem clima do tipo Cwa, temperado chuvoso-mesotérmico, a preci pitação média anual nos últimos nove anos foi de $1.236 \mathrm{~mm}$, com a evapotranspiração potencial anual estimada entre 800 e $850 \mathrm{~mm}$. A vegetação original era constituída, predominantemente, por floresta estacional semidecidual. O solo do local foi classificado como Latossol o Vermel ho-Amarelo álico textura franco-argilo-arenosa.

O Eucalyptus grandis (procedência Coffs Harbour) foi plantado em vários espaçamentos, em dezembro de 1991. As densi dades populacionais (DP) avaliadas foram 500, 625, 833, 1.250, 1.666, 2.500 e 5.000 plantas ha-1, correspondentes às áreas iniciais disponíveis por planta (AID) de 20, 16, 12, 8, 6, 4 e $2 \mathrm{~m}^{2}$, respectivamente. Os efeitos de cada tratamento foram aval iados em três repetições, em delineamento de bl ocos ao acaso. Cada parcela apresenta uma área total de $500 \mathrm{~m}^{2}(25 \times 20 \mathrm{~m})$.

Para o monitoramento da água no solo, feito com sonda de nêutrons (modelo 503 DR-CPN corp.), foram instalados, em cada parcela, três tubos de alumínio (com $45 \mathrm{~mm}$ de diâmetro externo) para acesso da sonda. Os val ores de contagem de nêutrons moderados foram convertidos em val ores de umi dade volumétrica $(\theta)$, com base na curva de cali bração da sonda $[\theta=-17,03+20,679$ (taxa relativa de contagem) $\left.R^{2} 0,879\right]$, ajustada a partir de dados obtidos em local ao lado da área experimental.

Dos três tubos de acesso de cada parcela, dois (de 2,0 $\mathrm{m}$ ) foram introduzidos atéa profundidade de 1,95 e um (de 3,0 m) até 2,95 m. U m dos tubos de 2,0 m foi instaladoa 0,5 m da árvoremédia de cada parcela, na entrelinha; o tubo de 3,0 m em um ponto central, definido pela interceptacão de duas diagonais tiradas de quatro árvores (da média e mais três árvores vizinhas); e o outro de $2,0 \mathrm{~m}$ no centro do triângulo formado entre o tubo central eduas árvores vizinhas na linha de plantio (Figura 1). 


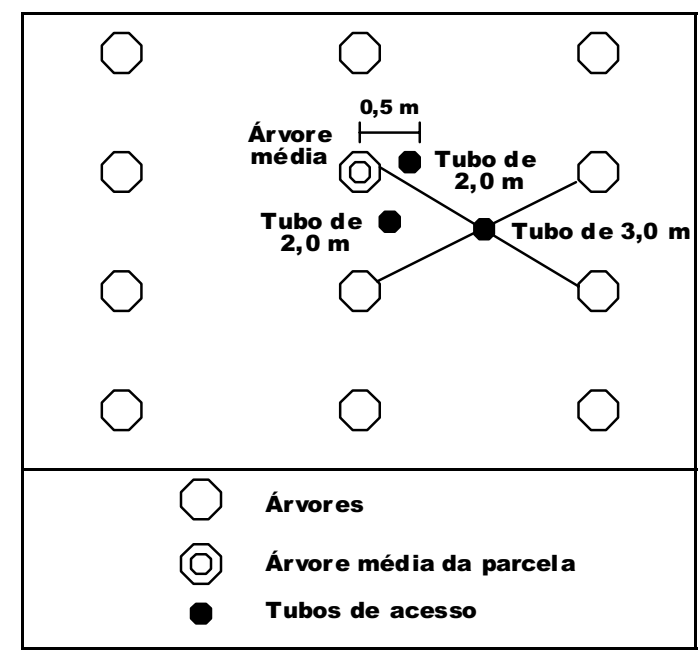

Figura 1. Distribuição esquemática dos tubos de acesso da sonda de nêutrons nas parcelas.

As leituras foram feitas em interval os quinzenais, durante o período de seis meses (de 12/08/94 a 16/ 02/95), nas seguintes profundidades: 30; 60; 90; 120 ; $150 ; 180 \mathrm{~cm}$. Adicional mente, no tubo de $3,0 \mathrm{~m}$, foram feitas leituras a 210, 240 e $270 \mathrm{~cm}$ de profundidade.

A partir do conteúdo de água no solo (conteúdo = $\theta \mathrm{em} \mathrm{cm}^{3} \mathrm{~cm}^{-3} \times$ profundidade da camada em $\mathrm{m} \mathrm{x}$ 10.000) em cada período de monitoramento, calcularam-se os índices: conteúdo médio (CM), média dos conteúdos de água no solo dos treze períodos avaliados; conteúdo médio relativo (CMR), média dos valores relativos de conteúdo (representando a fração do conteúdo de água da seção de controle, em cada período, em relação ao conteúdo máximo determinado na parcela correspondente a cada tratamento, durante o período total de monitoramento. A esse conteúdo máximo foi atribuído oval or relativo de $100 \%$, ou seja, nessa situação, o solo estava na sua capacidade máxima de armazenamento de água); val or máximo relativo de recarga (VMRC), diferença entre o conteúdo mínimo relativo encontrado na seção de controle antes de o solo ter atingido sua capacidade máxima de armazenamento e o val or máximo; val or máximo relativo de exaustão (VMRE), diferença entre o conteúdo mínimo relativo deágua no solo (após este ter alcançado seu conteúdo máximo) e este valor máximo.

Esses indicadores foram determinados a partir das seguintes considerações: Conteúdo (C) = conteúdo água no solo em cada período (média das profundidades, dos tubos e das parcelas), referente a cada tratamento; Conteúdo médio $(\mathrm{CM})=\Sigma \mathrm{C} /$ número de períodos; Conteúdo máximo (Cmax) corresponde ao maior conteúdo de água encontrado durante os períodos monitorados; Conteúdo relativo $(\mathrm{Cr})=(100 \times \mathrm{C}) / \mathrm{Cmax}$; Conteúdo médio relativo
$(\mathrm{CMR})=\Sigma \mathrm{Cr}$ /número de períodos; Conteúdo mínimo relativo (Cmin) corresponde ao conteúdo mínimo de água encontrado no período seco, antes do solo atingir seu conteúdo relativo máximo $\left(\mathrm{Cmax}_{r}\right)$ sendo $\mathrm{Cmax}_{\mathrm{r}}=100 \%$; Valor máximo relativo de recarga $\left(\mathrm{VMRC}=\mathrm{Cmax}_{\mathrm{r}}-\mathrm{Cmin}\right)$; Conteúdo de exaustão (Ce) = conteúdo mínimo encontrado no solo no período chuvoso, após o solo ter atingido seu conteúdo relativo máximo; Valor máximo relativo de exaustão (VMRE = Ce - Cmax), indica, em termos relativos, quanto de água foi extraída do solo em um período em que não havia restrição de água no solo.

Para a avaliação da precipitação pluviométrica interna, foram instalados três pluviômetros, em cada parcela, à altura de 1,5 m da superfície do solo. A distribuição dos pluviômetros dentro da parcela foi a mesma utilizada para os tubos de acesso de alumínio. Em área aberta, fora do experimento, foram instalados mais dois pluviômetros para a determinação da precipitação total .

Em trincheiras abertas ao lado do local do experimento, para a cali ibração da sonda de nêutrons, foram col etadas amostras de sol o para determinação da densidade do solo, densidade de partículas, textura e curva de retenção de água no solo em amostras indeformadas.

Também foi avaliado o efeito dos tratamentos na produção de bi omassa da parte aérea do eucal ipto e na interceptação da radiação fotossinteticamente ativa pelas copas das árvores. A matéria seca total da biomassa da parte aérea (BT) foi quantificada a partir da árvore média de cada parcela, que foi abatida e teve todos seus componentes (folha -F-, casca, gal ho e lenho) pesados e amostrados para a determinação de umidade.

A área foliar foi determinada a partir de amostras de $120 \mathrm{~g}$ de fol has, coletadas após homogeneização rigorosa de toda a fol hagem da árvore média. A área foliar dessas amostras foi avaliada por um medidor de área (Delta-T). Relacionando a área medida dessas amostras com o peso total da fol hagem verde, determinou-se a área foliar da árvore média. Dividindo essa área pela área disponível por planta, obteve-se o índice de área foliar (IAF).

A densidade defluxo defótons fotossinteticamente ativos foi medida com o fotômetro modelo DataL ogger LI 1.000, utilizando o sensor Quantum. Essa avaliação foi feita no período do dia quando o sol estava "mais alto" (mais próximo do zênite), em dia não nublado. As leituras foram tomadas em dezoito pontos dentro de cada parcela, sendo seis na linha, seis na entrelinha e seis na faixa central da diagonal entre duas árvores; os pontos deleitura em cada seqüência de seis ficaram distanciados $20 \mathrm{~cm}$. Também foi feita uma medição em uma área a pleno sol, próxima do local do experimento. Por diferença entre as determinações feitas dentro e fora do povoamento, determinou-se a radiação interceptada (RI). 


\section{RESULTADOS E DISCUSSÃO}

O solo da área experimental apresentou as seguintes características físico-hídricas (valores médios de amostras col etadas em seis profundidades no horizonte Bw): densidade do solo - 1,1 kg dm-3; densidade de partículas $2,57 \mathrm{~kg} \mathrm{dm}^{-3}$; areia fina, areia grossa, siltee argila - 120, 350, 210 e $320 \mathrm{~g} \mathrm{~kg}^{-1}$, respectivamente; porosidade, equivalente de umidade, umidade volumétrica correspondente àquela retida no solo a tensões de 0,01, 0,03 e $1,5 \mathrm{MPa}-0,57,0,21,0,289,0,219,0,168 \mathrm{~m}^{3} \mathrm{~m}^{-3}$, respectivamente.

A precipitação pluviométrica interna mostrou tendência de decréscimo linear com o aumento da densidade populacional, decorrente da maior interceptação da chuva pelas copas (INT) nas parcelas em que o espaçamento entre plantas era menor, em razão do mai or índi ce deárea fol iar observado nessas situações (Leite, 1996). A relação entre o percentual de chuva interceptada pelas copas (INT) e a área inicial disponível por plantas (AID) é descrita pela equação INT $=21,536-0,194$ AID $\left(R^{2}=0,57 *\right)$. Os val ores estimados de interceptação (de 17,6 a 21,1\%) estão dentro dos limites encontrados para espécies do gênero Eucalyptus. Lima (1993) cita resultados obtidos por vários autores que mostram perdas por interceptação entre 7 e 24\%, que impõem redução considerável na quantidade de água de chuva que chega à superfície do solo.

Nestetrabal ho, não se determinou a quantidade de água que atinge o solo via escorrimento pelo tronco. Caso essa via de entrada tivesse sido quantificada, certamente haveria redução dos valores de interceptação de água pelas copas, determinados somente pela diferença entre a precipitação total e interna.

Outro fato a ser considerado no ciclo hidrológico em florestas é a interceptação de água pela manta orgânica (M.O.) depositada no piso florestal. A quantidade de manta decresceu com o aumento da área inicial disponível por plantas [M.O. (t ha-1) $=$ 8,238 - 0,2296 AID (R2 0,914**)] (Leite, 1996). Assim, é possível que tenha havido mai or retenção de água pela manta nas parcelas com maior população de plantas. Por outro lado, a manta também contribui para maior infiltração de água no solo (Kowalik et al., 1988; Ole-Meiluidie \& Njau, 1989) e diminuição da evaporação direta da água do sol o, o que poderia contrabalançar o efeito anterior.

As variações da umidade vol umétrica do solo ao longo do tempo acompanham o comportamento da precipitação pluviométrica observada no mesmo período, e o padrão das variações não é diferente no solo sob diferentes populações de plantas. Em camadas acima de 1,65 m de profundidade (zona com a maior quantidade de raízes e onde existia a menor variabilidade espacial do solo), a umidade foi menor
(Figura 2), em termos absolutos, nos solos sob populações mais densas, o que pode ser reflexo tanto de maior uso de água, como da menor precipitação interna (mai or interceptação) (Stoneman \& Shofield, 1989). A afirmativa em relação à maior variabilidade do solo em profundidade é feita com base na constatação, durante a abertura dos orifícios para a instalação dos tubos de acesso, de que o material encontrado a partir de profundidades maiores que 2,3 m nem sempre era o mesmo. Em algumas situações, encontrava-se material de horizonte Bw (predominantemente); em outras, do B/C, e, em outras, material do horizonte C. Como esses materiais apresentavam características estruturais e texturais diferentes, seu comportamento hídrico também deverá ser diferenciado.

Portanto, optou-se por fazer algumas interpretações somente consi derando o regi me hídrico do solo até a camada de 1,65 m, onde, consistentemente (e até $0,65 \mathrm{~m}$ abaixo dessa profundidade) só foi encontrado horizonte Bw. Os val ores mais el evados dos coeficiente de variação dos resultados de umidade nas camadas mais profundas também indicam a possível variabilidade de algumas características do sol o nessas camadas (Quadro 1).

Os índices conteúdo médio (CM ), conteúdo médio relativo (CMR), valor máximo relativo de recarga (VMRC), valor máximo relativo de exaustão(VMRE) e umidade mínima no perfil (UMP), apresentados no quadro 2, também foram determinados para a seção de controle de 0 a $165 \mathrm{~cm}$ de profundidade. Isso foi feito para caracterizar o regime hídrico em camada de atividade radicular mais intensa e evitar possíveis interferências de variações de umidade em função da variabilidade do solo, encontrada na área experimental em profundidades maiores que $2,3 \mathrm{~m}$, que poderiam distorcer o efeito causado pel os tratamentos avaliados.

O conteúdo médio ( $\mathrm{CM}$ ) de água no solo mostra tendência de decréscimo com o aumento da densidade populacional (Quadro 2), principalmente quando excluídas dessas comparações as camadas mais profundas monitoradas. Em camadas mais profundas, as variações de água devem ter ocorrido mais em função de características do solo (estruturais e texturais) do que da densidade de plantas.

Os valores máximos relativos de recarga (VMCR), que indicam o quanto o sol o estava afastado de sua capacidade máxima de armazenamento de água, no período em que a umidade do solo atingiu seu valor mais baixo duranteo períodototal de monitoramento, mostraram tendências de variação definidas entre os tratamentos na camada de 0 a $165 \mathrm{~cm}$ (Quadro 2). Esses val ores confirmam a mesma tendência já apresentada pelos valores absolutos de umidade, representados pelo conteúdo médio (Figura 2).

Com relação ao esgotamento de água durante o período de el evada disponibilidade de água no solo, avaliada pelo valor máximo relativo de exaustão 


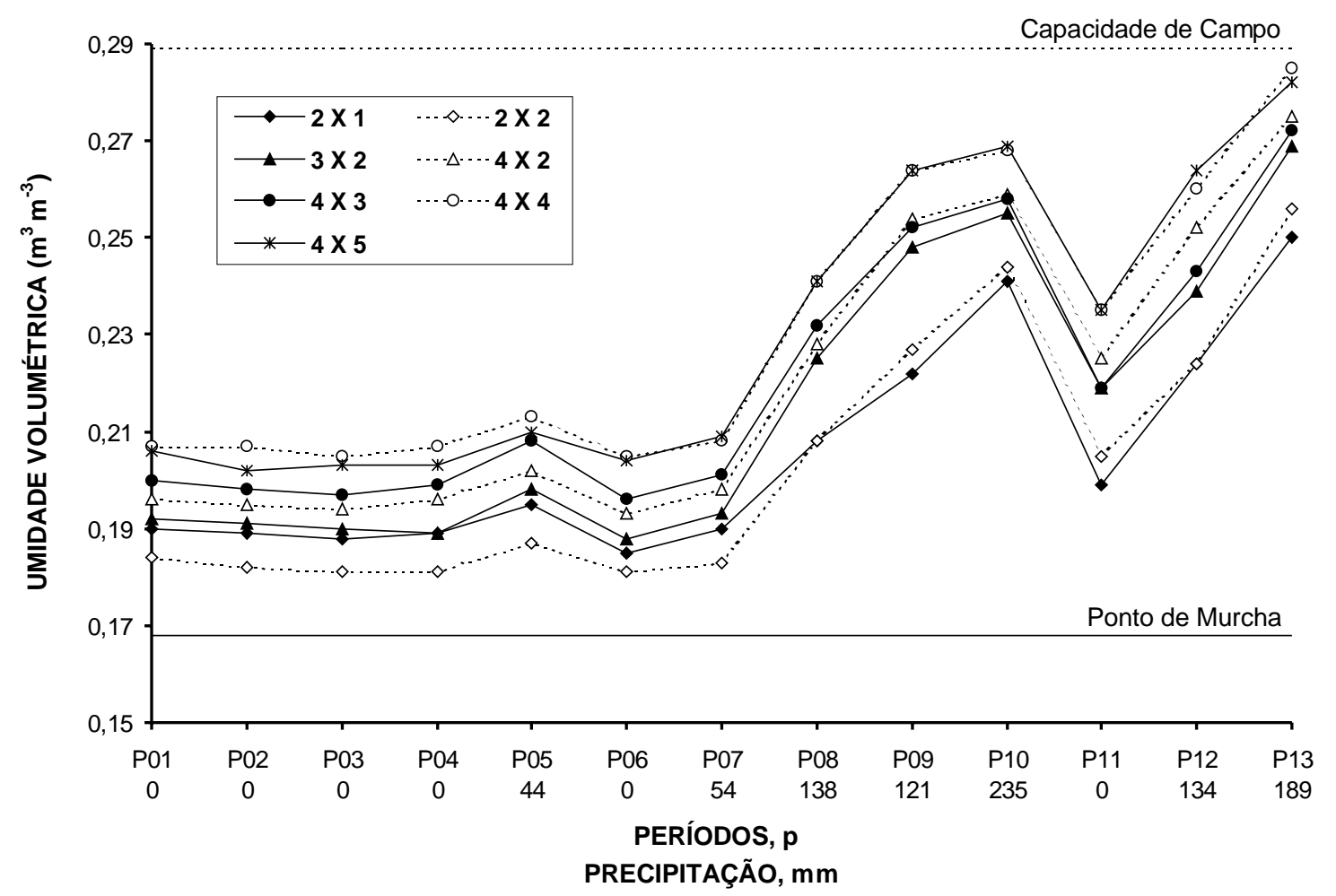

Figura 2. Umidade volumétrica do solo (camada de 0 a $165 \mathrm{~cm}$ ) determinado quinzenalmente (12/08/94-P1 até 16/02/95 - P 13) sob E .grandis estabelecido em diferentes espaçamentos e precipitações pluviométricas ocorridas nesses períodos.

Quadro 1. Coeficiente de variação (C.V.) dos valores de umidade determinados em diferentes profundidades, no período seco (PS) e no período das chuvas (PC)

\begin{tabular}{cccc}
\hline Profundidade & C.V. (PS) & Profundidade & C.V. (PC) \\
\hline $\mathrm{cm}$ & $\%$ & $\mathrm{~cm}$ & $\%$ \\
30 & 7,46 & 30 & 5,14 \\
60 & 3,99 & 60 & 3,38 \\
90 & 5,16 & 90 & 5,30 \\
120 & 5,05 & 120 & 5,25 \\
150 & 14,11 & 150 & 13,26 \\
180 & 22,37 & 180 & 18,33 \\
210 & 17,96 & 210 & 12,13 \\
240 & 16,63 & 240 & 14,33 \\
270 & 21,61 & 270 & 19,87 \\
\hline
\end{tabular}

(VMRE), as diferenças encontradas entre os tratamentos não são el evadas (Quadro 2), mas apresentam tendência de acréscimo com o aumento da população de plantas. Nesta situação, o maior esgotamento estaria diretamente ligado à evapotranspiração, já que, no período considerado para o cál culo desse índice (VMRE), não ocorreram chuvas, e os teores deágua nolimiteinferior do perfil monitorado estavam próximos aos valores verificados no período mais seco. I sso indica que as possíveis perdas deágua por percol ação interna para regiões abaixo daquela camada monitorada devem ter sido mínimas nessa época. Os valores médios de umidade mínima da seção de controle (UMP) de 0 a $165 \mathrm{~cm}$ (Quadro 2), para nenhum dos tratamentos avaliados, apresentou valores inferiores àquele correspondenteà umi dade retida no solo sob a tensão de $1,5 \mathrm{MPa}$, isto é, $16,82 \%$.

Com base nestes valores, pode-se afirmar que, durante o período monitorado, o eucalipto não utilizou a água que estava retida no solo a tensões maiores que 1,5 MPa. Espécies como $E$. saligna (Lima \& Reichardt, 1977), E. grandis (Zakia, 1980) e Pinus radiata (Myers \& Talsma, 1992) ainda conseguiram manter o transporte de água do solo para a atmosfera mesmo quando el a estava retida a tensões maiores que 1,5 MPa.

Durante o período em que não foram observadas variações de água no limite inferior do perfil monitorado, o que aconteceu até o dia 08/12/94, estimou-se a evapotranspiração da cultura (ETC). I sso foi feito por meio do balanço entre a quantidade de água que entrou no sistema via precipitação 
Quadro 2. Índices relacionados com características hídricas do solo, sob povoamentos de eucalipto, em diferentes espaçamentos, nas camadas de 0 a $165 \mathrm{~cm}$ de profundidade (165) e de 0 a $285 \mathrm{~cm}$ (285)

\begin{tabular}{|c|c|c|c|c|c|c|c|c|c|c|}
\hline \multirow{2}{*}{ Espaçamento } & \multicolumn{2}{|c|}{$\mathbf{C M}$} & \multicolumn{2}{|c|}{$C M R^{(1)}$} & \multicolumn{2}{|c|}{$\operatorname{VMRC}^{(1)}$} & \multicolumn{2}{|c|}{ VMRE $^{(1)}$} & \multicolumn{2}{|c|}{ UMP } \\
\hline & 165 & 285 & 165 & 285 & 165 & 285 & 165 & 285 & 165 & 285 \\
\hline $\mathrm{m}$ & \multicolumn{2}{|c|}{$\mathrm{m}^{3} \mathrm{ha}^{-1}$} & & & & & & & \multicolumn{2}{|c|}{$-\mathrm{m}^{3} \mathrm{~m}^{-3}$} \\
\hline $4 \times 5$ & 3.802 & 6.497 & 0,857 & 0,835 & 0,246 & 0,253 & $-0,125$ & $-0,105$ & 0,203 & 0,204 \\
\hline $4 \times 4$ & 3.814 & 6.185 & 0,862 & 0,833 & 0,233 & 0,246 & $-0,126$ & $-0,116$ & 0,206 & 0,196 \\
\hline $4 \times 3$ & 3.647 & 6.109 & 0,858 & 0,843 & 0,236 & 0,225 & $-0,149$ & $-0,121$ & 0,197 & 0,197 \\
\hline $4 \times 2$ & 3.639 & 6.245 & 0,850 & 0,843 & 0,253 & 0,234 & $-0,132$ & $-0,107$ & 0,194 & 0,199 \\
\hline $3 \times 2$ & 3.548 & 5.531 & 0,844 & 0,786 & 0,255 & 0,306 & $-0,142$ & $-0,123$ & 0,190 & 0,165 \\
\hline $2 \times 2$ & 3.354 & 5.615 & 0,833 & 0,835 & 0,261 & 0,234 & $-0,158$ & $-0,109$ & 0,180 & 0,180 \\
\hline $2 \times 1$ & 3.392 & 5.675 & 0,852 & 0,887 & 0,219 & 0,163 & $-0,171$ & $-0,114$ & 0,188 & 0,188 \\
\hline
\end{tabular}

$\mathrm{CM}=$ conteúdo médio de água no solo; $\mathrm{CMR}=$ conteúdo médio relativo; $\mathrm{VMRC}=$ valor máximo relativo de recarga; $\mathrm{VMRE}=$ valor máximo relativo de exaustão deágua do sol o; UMP =umi dade mínima observada na seção de controle. ${ }^{(1)}$ Valor relativo (adimensional).

pluviométrica interna e pelas variações de umidade no perfil monitorado ou somente pelas variações de umidade, nos períodos em que não houve precipitação. A ausência de escoamento superficial deveu-se à proteção dada pela manta orgânica à camada superficial do solo, bem como à baixa intensidade das chuvas ocorridas nesse período.

A evapotranspiração da cultura em nenhuma época apresentou diferenças consistentes entre os tratamentos avaliados (Quadro 3). Duranteo período de baixa disponibilidade deágua no sol o (P2), ovalor encontrado para ETc chegou a ser 22,6 vezes menor que o valor máximo observado. $\mathrm{Na}$ época de maior disponibilidade de água, maiores valores de água disponível (AD) nem sempre corresponderam a maiores valores de evapotranspiração da cultura, confirmando que a transpiração não é controlada somente pela disponibilidade de água do solo. Consi derando a não-existência degrandes diferenças na ETc entre as situações avaliadas (Quadro 3), pode-se inferir que os maiores valores do conteúdo de água observados nas parcelas com maiores espaçamentos ocorreram, principalmente, em função das diferenças na preci pitação interna, o quetambém foi constatado por Stogsdill et al. (1992) para Pinus taeda sob três níveis de desbaste.

Calculando os valores médios deevapotranspiração da cultura para as três populações com maior espaçamento e para as três com menor, nos períodos de menor (P1, P2 e P3) e de maior (P5, P6 e P7) disponibilidade deágua no solo, obtiveram-se asETc médias, nas parcelas com plantas com maior espaçamento, de 0,91 e 4,48 $\mathrm{mm} \mathrm{d}^{-1}$, e nas parcelas com plantas com menor espaçamento, de 0,74 e $4,58 \mathrm{~mm} \mathrm{~d}-1$, no período seco e no de maior disponibilidade de água, respectivamente. Tais resultados indicam que, nas parcelas correspondentes às maiores densidades de plantas (menor espaçamento), a ETc tende a ser um pouco menor no período seco e um pouco maior no período de maior disponibilidade de água no sol o. Observase quea maior ETcnas parcelas mais densas durante o período de el evada disponibilidade de água não é mantida durante os períodos em que ocorre decrésci mo dessa disponibilidade. Os val ores médios encontrados neste trabal ho para evapotranspiração da cultura no período de menor $(0,96)$ e maior $\left(4,61 \mathrm{~mm} \mathrm{~d}^{-1}\right)$ disponibilidade de água no solo são menores do que os encontrados por Grieve (1956), citado por Lima (1993), para E. grandis aos três anos no inverno $(2,1)$ e no verão $\left(5,7 \mathrm{~mm} \mathrm{~d}^{-1}\right)$.

Com os valores de umidade determinados, calcularam-se valores de umidade média de camadas acumuladas em várias profundidades nos perfis, para o período total de monitoramento (12/08/94 a 16/02/95). Determinaram-se os coeficientes de correlação $(r)$ entre estes valores de umidade em todos os tratamentos e características de crescimento (por área) e interceptação da radiação (Leite, 1996).

Para todas as características correlacionadas, os maiores valores de coeficientes foram encontrados para as correlações feitas com valores de umidade integrando as camadas até $195 \mathrm{~cm}$ de profundidade (Quadro 4), onde foram observadas $81,1 \%$ das variações de umidade entre o período seco e o chuvoso na seção de controle total ( 0 a $285 \mathrm{~cm}$ ).

Quando se considerou somente a camada superficial (0-45), ou todo o perfil monitorado (0-285), os valores de $r$ foram menores (Quadro 4), evidenciando a menor relação da umidade nas camadas de 0-45 e 255-285 com o crescimento. Os valores der da camada superficial mostraram quea extração de água pelas raízes nesta camada não difere entre os tratamentos. $E$, no caso da umidade a maiores profundidades (255-285), os diferentes tipos de horizontes encontrados (Bw, B/C eC) devem ter exercido mai or influência no comportamento da 
Quadro 3. Evapotranspiração da cultura estimada pelo balanço hídrico em parcelas com eucalipto em diferentes espaçamentos

\begin{tabular}{|c|c|c|c|c|c|c|c|c|}
\hline Espaçamento & P1 & P2 & P3 & P4 & P5 & P6 & P7 & Média \\
\hline $\mathrm{m}$ & \multicolumn{8}{|c|}{$-\mathrm{mm} \mathrm{dia}{ }^{-1}$} \\
\hline $4 \times 5$ & 0,71 & 0,40 & 1,73 & 0,98 & 2,23 & 7,18 & 5,53 & 2,39 \\
\hline $4 \times 4$ & 0,64 & 0,41 & 2,08 & 0,87 & 2,51 & 6,43 & 4,46 & 2,49 \\
\hline $4 \times 3$ & 0,20 & 0,29 & 1,72 & 1,74 & 2,20 & 7,10 & 4,68 & 2,56 \\
\hline $4 \times 2$ & 0,26 & 0,17 & 1,77 & 1,45 & 2,56 & 6,63 & 4,07 & 2,42 \\
\hline $3 \times 2$ & 0,63 & 0,39 & 1,61 & 1,75 & 2,97 & 4,94 & 4,01 & 2,33 \\
\hline $2 \times 2$ & 0,42 & 0,12 & 1,80 & 1,15 & 2,34 & 6,16 & 4,71 & 2,38 \\
\hline $2 \times 1$ & 0,20 & 0,27 & 1,21 & 2,05 & 2,41 & 7,84 & 5,85 & 2,83 \\
\hline Média & 0,44 & 0,29 & 1,70 & 1,43 & 2,46 & 6,61 & 4,76 & 2,48 \\
\hline Prec. (mm) & 0,0 & 0,0 & 43,7 & 0,0 & 53,9 & 137,8 & 121,1 & \\
\hline A.D.A. $\left(\mathrm{m}^{3} \mathrm{~m}^{-3}\right)$ & 0,277 & 0,263 & 0,299 & 0,294 & 0,268 & 0,434 & 0,685 & \\
\hline
\end{tabular}

P1 = corresponde às determinações feitas entre 12 a 24/08; P2 =24/08 a 13/09; P3 =28/08 a 13/10; P4 =13 a 26/10; P5 =26/10 a $11 / 11 ; \mathrm{P} 6=11 / 11$ a 24/11; P7 =24/11 a 08/12. Prec. = precipitação total em cada período; A.D.A =água disponível atual $(\theta$ atual $-\theta$ à $1,5 \mathrm{MPa})$.

água nessas camadas do que a atividade radicular, a qual, também, já deve ter sido bem mais reduzida a esta profundidade.

Os coeficientes de correlação (Quadro 4) também mostraram que: - aumentos no espaçamento de plantio (EA) propiciam maiores conteúdos de água no solo (ao se considerar uma seção de controle mais espessa); - quanto maior a biomassa foliar (F) ou o índice de área foliar (IAF), menor o conteúdo total

Quadro 4. Coeficientes de correlação linear simples entre umi dade volumétrica em várias camadas do solo, sob povoamentos de eucalipto em diferentes densidades populacionais com algumas características de crescimento e radiação interceptada

\begin{tabular}{clllll}
\hline Camada (cm) & EA & RI & F & BT & IAF \\
\hline 0- 45 & 0,59 & $-0,50$ & $-0,73^{*}$ & 0,47 & 0,68 \\
$0-75$ & $0,89^{* *}$ & $-0,82^{*}$ & $-0,90^{* *}$ & $-0,81^{*}$ & $-0,88^{*}$ \\
$0-105$ & $0,95^{* *}$ & $-0,92^{* *}$ & $-0,92^{* *}$ & $-0,93^{* *}$ & $-0,90^{* *}$ \\
$0-135$ & $0,97^{* *}$ & $-0,94^{* *}$ & $-0,89^{* *}$ & $-0,97^{* *}$ & $-0,92^{* *}$ \\
$0-165$ & $0,94^{* *}$ & $-0,93^{* *}$ & $-0,88^{* *}$ & $-0,99^{* *}$ & $-0,85^{* *}$ \\
$0-195$ & $0,92^{* *}$ & $-0,94^{* *}$ & $-0,82^{*}$ & $-0,99^{* *}$ & $-0,81^{*}$ \\
$0-225$ & $0,96^{* *}$ & $-0,95^{* *}$ & $-0,82^{*}$ & $-0,98^{* *}$ & $-0,87^{* *}$ \\
$0-255$ & $0,93^{* *}$ & $-0,90^{* *}$ & $-0,76^{*}$ & $-0,92^{* *}$ & $-0,85^{* *}$ \\
$0-285$ & $0,83^{*}$ & $-0,78^{*}$ & $-0,66$ & $-0,80^{*}$ & $-0,78^{*}$ \\
\hline
\end{tabular}

$\mathrm{EA}=$ espaçamento atual $\left(\mathrm{m}^{2}\right), \mathrm{RI}=$ radiação interceptada $(\mathrm{mmol}$ fotons $\left.\mathrm{m}^{2}\right), \mathrm{F}=$ matéria seca de fol ha $\left(\mathrm{t} \mathrm{ha}^{-1}\right), \mathrm{BT}=$ matéria seca da biomassa total da parte aérea $\left(\mathrm{t} \mathrm{ha} \mathrm{h}^{-1}\right), \mathrm{IAF}=$ índice de área foliar em $\left(\mathrm{m}^{2} \mathrm{~m}^{-2}\right)$.*,** significativos a 5 e $1 \%$ pelo teste $\mathrm{F}$. de água no solo e maior a biomassa total (BT) produzida, o que pode implicar maior eficiência hídrica das plantas; - a quantidade de radiação inter ceptada, em razão de maior I AF ou massa fol iar, interfere no conteúdo deágua no solo. Nas situações em que houve maior interceptação, maior quantidade de energia luminosa foi convertida em energia química (Leite, 1996), levando ao maior crescimento e aumentando a demanda de água ou reduzindo a preci pitação efetiva, conforme indicado pel os coeficientes de correlação entre o conteúdo de água no sol o e a radiação interceptada.

\section{CONCLUSÕES}

1. Para locais onde a manutenção de maior disponibilidade de água no solo é importante, recomenda-se que o cultivo do eucalipto seja feito em menores densidades populacionais.

2. A redução da densidade populacional tende a aumentar o conteúdo de água no solo, princi palmente em decorrência do aumento da precipitação pluviométrica interna nessas situações.

3. As plantas deEucalyptus grandis, em nenhuma das situações avaliadas, chegaram a utilizar água do solo que estivesse retida a tensões maiores que 1,5 $\mathrm{MPa}$.

4. $\mathrm{Na}$ idade do povoamento em que foram efetuadas as aval iações, o crescimento do Eucal yptus grandis parece ser mais dependente da água retida na camada de solo compreendida entre 45 e $255 \mathrm{~cm}$. 


\section{LITERATURA CITADA}

GOMES, R.T. Efeito do espaçamento no crescimento e nas relações hídricas de Eucalyptus spp. na região de cerrado de Minas Gerais. Viçosa, Universidade Federal de Viçosa, 1994. 85p. (Tese de Mestrado)

KOWALIK, P.J .; BORGHETTI, M.; BUSONI, E.; SANESI, G. \& VENDRAMIN, G.G. Measured and simulated water relations in a douglas-fir forest during the development of drought in the Apennines, Central Italy. For Ecol. Manag., 25:181-194, 1988.

KRAMER, P.J. Water relations of plants. New York, Academic Press, 1983. 489p.

LEITE, F.P. Crescimento, relações hídricas, nutricionais e lumínicas em povoamento de Eucalyptus grandis em diferentes densidades populacionais. Viçosa, Universidade Federal de Viçosa, 1996. 90p. (Tese de Mestrado)

LIMA, W.P. I mpacto ambiental do eucalipto. São Paulo, Universidade de São Paulo, 1993. 301p.
LIMA, W.P. \& REICHARDT, K. Regime de água do solo sob florestas homogêneas de eucal ipto e de pinheiro. Piracicaba, CENA, 1977. 31p. (Boletim Científico, 43)

MYERS, B.J . \& TALSMA, T. Site water balance and tree water status in irrigated and fertilised stands of Pinus radiata. For. Ecol. Manag., 52:17-42, 1992.

OLE-MEILUIDIE, R.E.L. \& NJ AU, W.L.M. Impact of logging equipment on water infiltration capacity at Olmotonyi, Tanzania. For. Ecol. Manag., 26:207-213, 1989.

STOGSDILL, W.R.; WITTWER J r., R.F.; HENNESSEY, T.C. \& DOUGHERTY, P.M. Water use in thinned loblolly pine plantations. For. Ecol. Manag., 50:233-245, 1992

STONEMAN, G.L. \& SCHOFIELD, N.J . Silviculture for water production in jarrah forest of Western Austrália: an evaluation. For. Ecol. Manag., 27:273-293, 1989.

ZAKIA, M.J .B. O balanço hídrico, levando-se em conta o sistema solo-planta-atmosfera, na região de Grão Mogol, MG. Piracicaba, Escola Superior deAgricultura Luíz de Queiroz, 1980. 125p. (Tese de Mestrado) 